\title{
Acute and Repeated 28-Day Oral Dose Toxicity Studies of Thymus vulgaris L. Essential Oil in Rats
}

\author{
Juan Rojas-Armas ${ }^{1}$, Jorge Arroyo-Acevedo', Manuel Ortiz-Sánchez ${ }^{2}$, Miriam Palomino-Pacheco ${ }^{3}$, \\ Américo Castro-Luna ${ }^{4}$, Norma Ramos-Cevallos ${ }^{4}$, Hugo Justil-Guerrero', Julio Hilario-Vargas ${ }^{5}$ and \\ Oscar Herrera-Calderón ${ }^{4}$ \\ ${ }^{1}$ Laboratory of Experimental Pharmacology, Institute of Clinical Research, Faculty of Medicine, National University of \\ San Marcos, Lima, Peru \\ ${ }^{2}$ Section of Physiology, Faculty of Medicine, National University of San Marcos, Lima, Peru \\ ${ }^{3}$ Section of Biochemistry, Faculty of Medicine, National University of San Marcos, Lima, Peru \\ ${ }^{4}$ Faculty of Pharmacy and Biochemistry, National University of San Marcos, Lima, Peru \\ ${ }^{5}$ Department of Physiology, School of Medicine, National University of Trujillo, Trujillo, Peru
}

\begin{abstract}
Thymus vulgaris L. is widely used as an ingredient in cooking and in herbal medicine. However, there is little information about its toxicity. The present study was performed to evaluate the acute and repeated 28-day oral dose toxicity of thyme essential oil in rats. For the acute toxicity test, two groups of three rats were used. The rats received a single dose of essential oil: 300 or $2,000 \mathrm{mg} / \mathrm{kg}$ of body weight (bw). The rats were observed individually during the first four hours, and then daily until day 14 . For the toxicity test with repeated doses, four groups of 10 rats were used. Doses of 100,250 , and $500 \mathrm{mg} / \mathrm{kg} /$ day were tested for 28 days. At the end of the experiment, blood was collected and the animals were sacrificed. Histopathological examination showed that in the lungs of rats given the $2,000 \mathrm{mg} / \mathrm{kg}$ bw dose, polymorph nuclear infiltrates, hemosiderin macrophages, and interstitial space thickening were present. In the repeated dose study, all rats survived the 28-day treatment period and apparently showed no signs of toxicity. The hematological and biochemical parameters were not altered. The histopathological study of the organs showed severe changes in the lung, with the dose of $500 \mathrm{mg} / \mathrm{kg} / \mathrm{day}$; in the other organs, no alterations were observed or the changes were slight. The body weight was only altered in male rats given the $500 \mathrm{mg} / \mathrm{kg}$ dose. The relative weight of the organs did not show any significant changes. Our studies revealed that the essential oil of Thymus vulgaris has moderate oral toxicity according to the results of the acute test, whereas the results of the 28-day oral toxicity test suggest that the no-observed-adverse effect level (NOAEL) is greater than $250 \mathrm{mg} / \mathrm{kg} /$ day.
\end{abstract}

Key words: Thymus vulgaris, Oral toxicity, Essential oil, Rats, NOAEL

\section{INTRODUCTION}

Thymus vulgaris L. (thyme), a member of the Lamiaceae family, is a grassy perennial plant that grows in many

Correspondence to: Juan Rojas Armas, Laboratory of Experimental Pharmacology, Institute of Clinical Research, Faculty of Medicine, National University of San Marcos, Lima 01, Peru E-mail: jprojasarmas@yahoo.com

This is an Open-Access article distributed under the terms of the Creative Commons Attribution Non-Commercial License (http:// creativecommons.org/licenses/by-nc/3.0) which permits unrestricted non-commercial use, distribution, and reproduction in any medium, provided the original work is properly cited. parts of the world. It is aromatic and rich in essential oil. Native to southern Europe, it is widely used in traditional medicine across the globe. In Peru, an infusion of this plant is used to improve cerebral and circulatory functions and to ward against intestinal parasites, whereas the essential oil is used as an antiseptic (1).

There are several studies that have reported the pharmacological activity of the essential oil of Thymus vulgaris, such as: antibacterial activity against Staphylococcus aureus, Escherichia coli, Bacillus cereus, Proteus vulgaris, Listeria monocytogenes, Propionibacterium acnes, Clostridium perfringens, Enterococcus faecalis, Salmonella typhimurium, and Yersinia enterolitica (2-7); antifungal activity against 
Candida albicans, Trichophyton mentagrophytes, Fusarium sp., Aspergillus flavus, and Aspergillus niger (8-11); antiparasitic effects against protoscoleces and cysts of Echinococcus granulosus (12) and Trypanosoma cruzi (13); cytotoxic activity against cells of human prostate carcinoma, human lung carcinoma, and human breast cancer (4); hepatoprotective effect against hepatic damage induced by acetaminophen in mice (14).

Recently, a study evaluated the potential of thyme essential oil and its individual components to reduce cholinergic deficits related to neurodegenerative and psychiatric disorders. The study revealed that thyme oil increases neurotransmission by modulating acetylcholine (Ach) synaptic levels and activity of the nicotinic acetylcholine receptor, orchestrated by the positive regulation of the cho-1, unc17, and unc-50 genes. Likewise, the active components para-cymene (1-methyl-4-propan-2-ylbenzene) and the combination of thymol and gamma-terpinene exhibited similar effects, with possible improvement in cholinergic dysfunction (15).

For several medicinal plants, information regarding their toxicity is limited $(16,17)$. Despite the fact that important pharmacological activities of thyme essential oil have been reported, no oral toxicity study of thyme essential oil has been published. However, oral toxicity studies of thymol, the main constituent of the essential oil of Thymus vulgaris, have already been reported in another study (18). Therefore we set out to evaluate the acute and repeated oral toxicity of Thymus vulgaris essential oil for 28 days in a murine model.

\section{MATERIALS AND METHODS}

Plant material. Thymus vulgaris L. was collected in the city of Lima, Peru. A sample was taken to the Natural History Museum of the National University of San Marcos for taxonomic identification (No. 184-USM-2016).

The essential oil was obtained from fresh leaves using steam distillation in a Clevenger-type apparatus (19). The oil was separated and dehydrated with anhydrous $\mathrm{Na}_{2} \mathrm{SO}_{4}$, filtered, and stored in an amber glass bottle under refrigeration at a temperature of $4^{\circ} \mathrm{C}$ until used.

Experimental animals and housing. Albino Holtzman rats were obtained from the National Health Institute, Peru. They were kept in cages for one week prior to commencing the study to allow for acclimatization to laboratory conditions. The animals' housing was maintained under controlled environmental conditions (12-hr light/ dark cycle) and temperature $\left(22 \pm 3^{\circ} \mathrm{C}\right)$. They were fed $\mathrm{ad}$ libitum with commercial rat feed and drinking water.

All the animal experiments were performed in accordance with institutional protocols and the guideline for care and use of laboratory animals (20). All research pro- tocols were submitted to, and approved by, the School of Medicine Research Ethics Committee, National University of San Marcos, Peru (Act No. 158).

Acute oral toxicity studies. Acute toxicity at a single dose was evaluated according to the Organization for Economic Co-operation and Development (OECD) guideline, method 423. This method is a step-by-step procedure that begins with the maximum dose of $2,000 \mathrm{mg} / \mathrm{kg}$ bw and, then depending on the mortality and/or morbidity of the animals, is lowered to 300,50 , or $5 \mathrm{mg} / \mathrm{kg}$ bw doses to allow a judgment of the test substance's acute toxicity (21). All the animals were fasted overnight before commencing the experiment. The experiment was conducted on six female rats $(160 \pm 10 \mathrm{~g} \mathrm{bw})$, randomly assigned to two groups $(n=3)$, which each received a single dose of essential oil (300 or $2,000 \mathrm{mg} / \mathrm{kg} \mathrm{bw}$ ). The animals were observed individually during the first $30 \mathrm{~min}$, with special attention during the first four hours, then daily throughout the 14 days of the experiment. Signs and symptoms of toxicity were recorded. Observations focused on the determination of death and time of occurrence, signs and symptoms of toxicity from the beginning and through the duration of the experiment, including changes in skin, fur, mucous membranes and eyes, respiratory and circulatory systems, central nervous and autonomic systems, somatomotor activity and behavior. Special attention was paid to the potential occurrence of tremors, seizures, salivation, diarrhea, lethargy, drowsiness, and coma. To conclude the experiment, the animals were sacrificed by inhalation of ethyl ether. This was followed by necropsy and macroscopic pathological study of the stomach, liver, spleen, lungs, kidneys, esophagus, brain, and small intestine. Finally, the organs were studied by microscopic examination.

Repeated dose 28-day oral toxicity study. The subchronic oral toxicity study was performed in accordance with the instructions by OECD test guideline-407 (22) with slight modifications, using 20 female rats $(160 \pm 10 \mathrm{~g}$ bw) and 20 male rats $(170 \pm 10 \mathrm{~g} \mathrm{bw})$. The animals were randomly assigned to four groups $(n=10$ : five female and five male). Each rat in Group I (control group) received only the vehicle. Groups II, III, and IV received the essential oil of Thymus vulgaris in repeated oral doses of 100 , 250 , and $500 \mathrm{mg} / \mathrm{kg}$ bw, respectively, for 28 days. The animals were dosed at approximately the same time each day. The animals were monitored for signs of toxicity and mortality twice a day (a.m. and p.m.) throughout the experimental period of 28 days. The terminal weight of each animal was recorded weekly throughout the course of the experiment. On day 29, blood samples were collected from the rats via intracardiac puncture, under anesthesia with ethyl ether, and assessed for hematological and biochemical parameters. 
The animals were sacrificed by decapitation under anesthesia with intraperitoneal sodium pentobarbital $(40 \mathrm{mg} /$ $\mathrm{kg}$ ). Organs were fixed in $10 \%$ formalin for histopathological examination.

Body and organ weight measurement. After treatments, the body weight of each rat in the experiment was measured and recorded. The heart, lungs, liver, spleen, stomach, kidney, and testes or uterus were excised immediately after sacrifice, trimmed of fat and connective tissue, blotted with filter paper and weighed. The relative organ weights [ratio of organ weight and the animal's body weight (at the end of experiment) $\times 100$ ] were calculated.

Biochemical parameters. Biochemical parameters were evaluated using a Semi-Automatic Biochemical Analyzer, model EMP-168 (Ivdiagnostik, Emperor Medical, Shenzhen, China), according to the manufacturer's specifications. The levels of aspartate aminotransferase (AST), alanine aminotransferase (ALT), alkaline phosphatase, total protein, bilirubin, cholesterol, triglycerides, high-density lipoprotein (HDL), low-density lipoprotein (LDL), total albumin, glucose, urea, and creatinine were determined.

Hematological assay. Hematological assays were performed using an Automatic Hematology Analyzer KT6400 (Genius, Med Equipment, Guangzhou, China). At the end of the experiment hematocrit, hemoglobin concentration, erythrocyte count, total and differential leukocyte counts, and platelet count were evaluated.

Histopathological analysis. All the animals were subjected to necropsy at the end of the oral toxicity study (or earlier in the case of death). The organs were preserved in $10 \%$ formalin and fixed for three days, dehydrated, embedded in paraffin, sectioned at $5 \mu \mathrm{m}$, and stained with hematoxylin/eosin. Slides of organs taken from all animals were examined microscopically and photographed with a light microscope (BX53, Olympus, Tokyo, Japan) at 100× and $400 \times$ magnification.

Statistical analyses. The data were expressed as mean \pm SD of five animals in each group and were analyzed using one-way analysis of variance (ANOVA), followed by the Tukey's test. The results were considered significant when $p<0.05$. IBM's SPSS version 19 was used for all statistical analyses

\section{RESULTS}

Acute oral toxicity. With the single dose of Thymus vulgaris essential oil $(2,000 \mathrm{mg} / \mathrm{kg} \mathrm{bw})$, the three rats in the group showed immediate signs of toxicity, including hyperactivity and burning nose. After $10 \mathrm{~min}$, ataxia, hypersalivation, and respiratory distress were observed. After four hours, one rat had recovered, while the other two rats worsened and went into lethargy with hypothermia, and finally coma. Death occurred within $24 \mathrm{hr}$. After these results were obtained, a single oral dose of $300 \mathrm{mg} /$ $\mathrm{kg}$ bw was administered to another group of rats. The three animals in the group all showed slight manifestations that completely disappeared within $3 \mathrm{hr}$.

Histopathological examination of organs showed alterations in the lungs, where polymorph nuclear infiltrates, hemosiderin macrophages, and interstitial space thickening were observed. In the kidneys, a polymorph nuclear infiltrate was observed in the pyelocaliceal area, and the liver showed a slight fatty infiltration. In the stomach, spleen, heart, and brain no alterations were observed.

Repeated dose 28-day oral toxicity studies. All rats survived the 28-day treatment period and showed no apparent signs of toxicity.

Effect of essential oil on body and organ weight of rats. There were no significant changes in body weight in female rats treated with the essential oil of Thymus vulgaris when compared to the control group. However, in
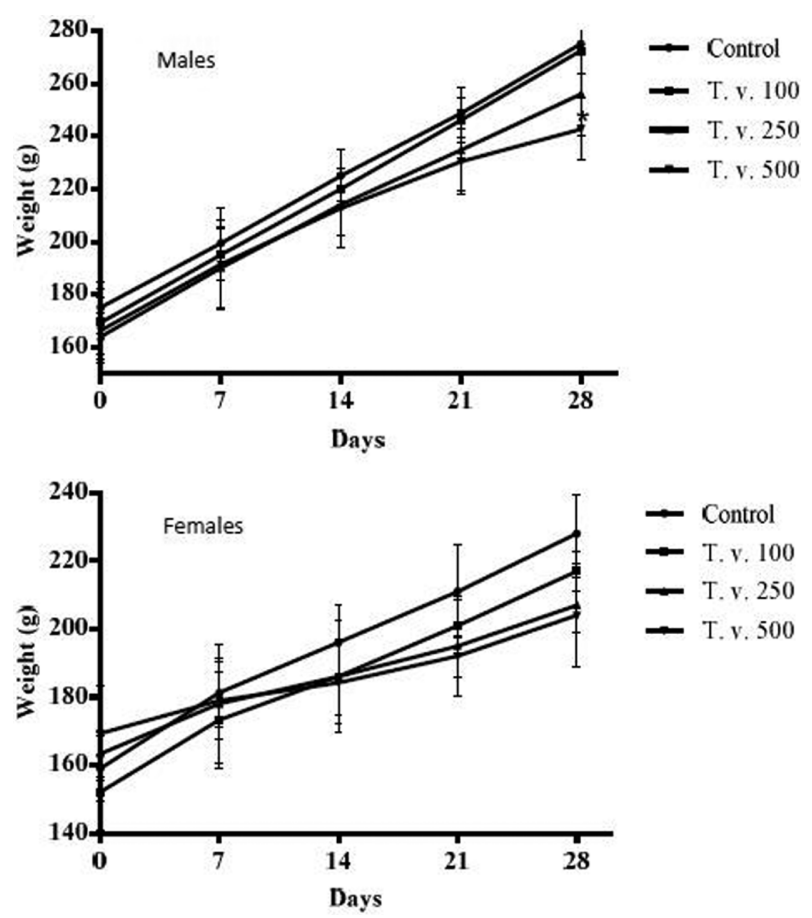

Fig. 1. Body weight in rats treated with Thymus vulgaris essential oil (T.v.) repeated oral doses $(100,250$, and $500 \mathrm{mg} / \mathrm{kg}$ ) for 28 days. No change was observed in females during the dosing period. A significant decrease was observed in males, but only with the $500 \mathrm{mg} / \mathrm{kg}$ dose, and during the fourth week. ${ }^{*} p<0.05$ compared to the control. 
Table 1. Effect of Thymus vulgaris essential oil on the relative weight of the organs in rats treated for 28 days

\begin{tabular}{lcccc}
\hline \hline & \multicolumn{4}{c}{ Dose group $(\mathrm{mg} / \mathrm{kg} /$ day $)$} \\
\cline { 2 - 5 } Organ & Control & 100 & 250 & 500 \\
\hline Males & & & & \\
Heart & $0.35 \pm 0.03$ & $0.33 \pm 0.07$ & $0.35 \pm 0.11$ & $0.36 \pm 0.03$ \\
Lungs & $0.72 \pm 0.09$ & $0.73 \pm 0.14$ & $0.81 \pm 0.10$ & $0.80 \pm 0.06$ \\
Liver & $3.13 \pm 0.16$ & $3.14 \pm 0.60$ & $2.97 \pm 0.40$ & $2.95 \pm 0.18$ \\
Spleen & $0.35 \pm 0.04$ & $0.34 \pm 0.17$ & $0.31 \pm 0.05$ & $0.35 \pm 0.02$ \\
Stomach & $0.54 \pm 0.08$ & $0.55 \pm 0.05$ & $0.55 \pm 0.21$ & $0.57 \pm 0.11$ \\
Kidney & $0.40 \pm 0.05$ & $0.43 \pm 0.08$ & $0.42 \pm 0.07$ & $0.44 \pm 0.07$ \\
Testis & $1.02 \pm 0.09$ & $1.07 \pm 0.14$ & $1.02 \pm 0.11$ & $1.07 \pm 0.19$ \\
Females & & & & \\
Heart & $0.34 \pm 0.14$ & $0.35 \pm 0.09$ & $0.33 \pm 0.07$ & $0.35 \pm 0.11$ \\
Lungs & $0.91 \pm 0.13$ & $0.90 \pm 0.22$ & $0.92 \pm 0.23$ & $0.89 \pm 0.26$ \\
Liver & $2.93 \pm 0.24$ & $3.17 \pm 0.57$ & $3.28 \pm 0.20$ & $3.05 \pm 0.22$ \\
Spleen & $0.41 \pm 0.11$ & $0.42 \pm 0.27$ & $0.39 \pm 0.03$ & $0.44 \pm 0.05$ \\
Stomach & $0.49 \pm 0.14$ & $0.49 \pm 0.14$ & $0.53 \pm 0.12$ & $0.54 \pm 0.26$ \\
Kidney & $0.35 \pm 0.08$ & $0.38 \pm 0.17$ & $0.40 \pm 0.21$ & $0.41 \pm 0.19$ \\
Uterus & $0.49 \pm 0.04$ & $0.51 \pm 0.12$ & $0.48 \pm 0.07$ & $0.49 \pm 0.18$ \\
\hline
\end{tabular}

Values are expressed as Mean \pm SD. No significant difference was observed when compared with controls. the male rats, a significant change occurred in the fourth week of the $500 \mathrm{mg} / \mathrm{kg}$ bw dose group, with body weight decreasing from $275.00 \pm 11.36 \mathrm{~g}$ (control group) to $242.67 \pm 11.93 \mathrm{~g}(p<0.05)$ (Fig. 1). The relative weight of the heart, lungs, liver, spleen, stomach, kidney, and testes of male rats, or uterus of female rats treated in the 28day period did not show any significant changes when compared with the control group (Table 1).

\section{Effect of essential oil on biochemical parameters.}

The biochemical parameters of both female and male rats showed no significant changes after the 28-day toxicity test when compared to the control group (Table 2).

\section{Effect of essential oil on hematological parameters.}

The results of the hematological parameters of control rats and those treated daily for 28 days with the essential oil of Thymus vulgaris are shown in Table 3 . These results show that there were no significant changes to any of the parameters in the treated groups when compared with the control group.

Table 2. Biochemical parameters of rats after treatment with repeated oral doses of Thymus vulgaris essential oil for 28 days

\begin{tabular}{|c|c|c|c|c|}
\hline \multirow{2}{*}{ Parameter } & \multicolumn{4}{|c|}{ Dose group (mg/kg/day) } \\
\hline & Control & 100 & 250 & 500 \\
\hline \multicolumn{5}{|l|}{ Males } \\
\hline AST (IU/L) & $145.00 \pm 6.55$ & $155.67 \pm 7.02$ & $159.67 \pm 4.51$ & $162.00 \pm 8.89$ \\
\hline ALT (IU/L) & $60.33 \pm 12.86$ & $73.00 \pm 7.94$ & $74.33 \pm 9.50$ & $75.67 \pm 10.02$ \\
\hline Alkaline phosphatase (IU/L) & $173.67 \pm 6.03$ & $190.33 \pm 8.74$ & $193.67 \pm 12.50$ & $194.67 \pm 9.87$ \\
\hline Total bilirubin $(\mathrm{mg} / \mathrm{dL})$ & $0.61 \pm 0.12$ & $0.65 \pm 0.25$ & $0.68 \pm 0.08$ & $0.67 \pm 0.07$ \\
\hline Total protein $(\mathrm{g} / \mathrm{dL})$ & $7.17 \pm 0.50$ & $7.23 \pm 0.60$ & $7.37 \pm 0.57$ & $7.47 \pm 0.32$ \\
\hline Albumin (g/dL) & $3.63 \pm 0.35$ & $3.89 \pm 0.09$ & $3.97 \pm 0.21$ & $4.03 \pm 0.15$ \\
\hline Cholesterol (mg/dL) & $68.40 \pm 5.05$ & $62.43 \pm 8.16$ & $64.00 \pm 7.21$ & $63.13 \pm 10.43$ \\
\hline Triglycerides (mg/dL) & $95.27 \pm 11.07$ & $84.03 \pm 6.99$ & $81.47 \pm 6.63$ & $80.53 \pm 2.84$ \\
\hline $\mathrm{HDL}(\mathrm{mg} / \mathrm{dL})$ & $35.10 \pm 6.71$ & $35.80 \pm 6.01$ & $35.07 \pm 4.65$ & $35.10 \pm 3.15$ \\
\hline $\mathrm{LDL}(\mathrm{mg} / \mathrm{dL})$ & $14.25 \pm 2.84$ & $9.82 \pm 2.02$ & $12.64 \pm 2.19$ & $11.92 \pm 2.77$ \\
\hline Glucose (mg/dL) & $118.10 \pm 7.41$ & $118.67 \pm 12.58$ & $119.00 \pm 6.56$ & $123.33 \pm 7.23$ \\
\hline Urea $(\mathrm{mg} / \mathrm{dL})$ & $35.50 \pm 2.29$ & $34.83 \pm 3.19$ & $37.23 \pm 3.95$ & $38.17 \pm 2.25$ \\
\hline Creatinine (mg/dL) & $0.75 \pm 0.18$ & $0.73 \pm 0.06$ & $0.84 \pm 0.07$ & $0.83 \pm 0.05$ \\
\hline \multicolumn{5}{|l|}{ Females } \\
\hline AST (IU/L) & $130.33 \pm 5.51$ & $131.00 \pm 6.56$ & $134.33 \pm 6.03$ & $136.67 \pm 7.09$ \\
\hline ALT (IU/L) & $58.67 \pm 9.71$ & $60.33 \pm 8.39$ & $66.00 \pm 12.17$ & $67.00 \pm 8.19$ \\
\hline Alkaline phosphatase (IU/L) & $174.00 \pm 9.64$ & $194.67 \pm 9.87$ & $180.33 \pm 12.50$ & $192.33 \pm 6.03$ \\
\hline Total bilirubin $(\mathrm{mg} / \mathrm{dL})$ & $0.62 \pm 0.14$ & $0.58 \pm 0.13$ & $0.63 \pm 0.08$ & $0.64 \pm 0.09$ \\
\hline Total protein $(\mathrm{g} / \mathrm{dL})$ & $7.23 \pm 0.67$ & $7.43 \pm 0.15$ & $7.47 \pm 0.21$ & $7.50 \pm 0.89$ \\
\hline Albumin $(\mathrm{g} / \mathrm{dL})$ & $3.80 \pm 0.20$ & $3.95 \pm 0.15$ & $4.07 \pm 0.21$ & $4.17 \pm 0.22$ \\
\hline Cholesterol (mg/dL) & $72.23 \pm 10.28$ & $72.50 \pm 6.73$ & $69.33 \pm 6.66$ & $70.10 \pm 5.46$ \\
\hline Triglycerides (mg/dL) & $89.07 \pm 6.21$ & $82.52 \pm 9.98$ & $79.17 \pm 8.89$ & $77.33 \pm 7.02$ \\
\hline HDL (mg/dL) & $36.03 \pm 4.65$ & $36.47 \pm 4.22$ & $34.47 \pm 4.08$ & $35.83 \pm 1.89$ \\
\hline $\mathrm{LDL}(\mathrm{mg} / \mathrm{dL})$ & $18.39 \pm 5.24$ & $19.53 \pm 3.14$ & $19.03 \pm 3.95$ & $18.80 \pm 4.11$ \\
\hline Glucose (mg/dL) & $120.07 \pm 6.26$ & $117.67 \pm 8.02$ & $122.47 \pm 6.43$ & $127.07 \pm 13.11$ \\
\hline Urea $(\mathrm{mg} / \mathrm{dL})$ & $37.93 \pm 1.69$ & $34.93 \pm 4.78$ & $33.40 \pm 3.22$ & $32.63 \pm 4.22$ \\
\hline Creatinine (mg/dL) & $0.78 \pm 0.06$ & $0.77 \pm 0.06$ & $0.81 \pm 0.07$ & $0.74 \pm 0.05$ \\
\hline
\end{tabular}

Values are expressed as Mean \pm SD. No significant differences were observed when compared with controls.

AST, aspartate aminotransferase; ALT, alanine aminotransferase; ALP, alkaline phosphatase; HDL, high-density lipoprotein; LDL, low-density lipoprotein. 
Table 3. Hematological parameters of rats after treatment with repeated oral doses of Thymus vulgaris essential oil for 28 days

\begin{tabular}{|c|c|c|c|c|}
\hline \multirow{2}{*}{ Parameter } & \multicolumn{4}{|c|}{ Dose group (mg/kg/day) } \\
\hline & Control & 100 & 250 & 500 \\
\hline \multicolumn{5}{|l|}{ Males } \\
\hline $\mathrm{RBC}\left(\times 10^{6} / \mu \mathrm{L}\right)$ & $7.25 \pm 0.12$ & $7.13 \pm 0.28$ & $7.21 \pm 0.23$ & $7.50 \pm 0.29$ \\
\hline $\mathrm{WBC}\left(\times 10^{3} / \mu \mathrm{L}\right)$ & $8.30 \pm 0.95$ & $8.20 \pm 0.60$ & $8.70 \pm 0.95$ & $8.60 \pm 1.85$ \\
\hline Hemoglobin (g/dL) & $14.87 \pm 0.80$ & $14.80 \pm 0.95$ & $15.17 \pm 0.65$ & $14.60 \pm 0.87$ \\
\hline Hematocrit (\%) & $46.73 \pm 2.05$ & $46.43 \pm 2.77$ & $47.07 \pm 2.53$ & $46.33 \pm 4.51$ \\
\hline Neutrophils (\%) & $18.00 \pm 2.00$ & $19.33 \pm 3.51$ & $23.67 \pm 4.51$ & $21.67 \pm 3.06$ \\
\hline Eosinophils (\%) & $2.67 \pm 0.58$ & $3.00 \pm 1.73$ & $2.33 \pm 1.53$ & $3.00 \pm 1.00$ \\
\hline Basophils (\%) & $0.67 \pm 0.58$ & $1.00 \pm 1.00$ & $1.00 \pm 1.00$ & $0.67 \pm 0.58$ \\
\hline Monocytes (\%) & $3.33 \pm 0.58$ & $3.00 \pm 1.00$ & $2.67 \pm 0.58$ & $3.33 \pm 1.15$ \\
\hline Lymphocytes (\%) & $75.33 \pm 2.52$ & $73.67 \pm 4.51$ & $70.33 \pm 5.03$ & $71.33 \pm 4.04$ \\
\hline Platelets $\left(\times 10^{3} / \mu \mathrm{L}\right)$ & $700.67 \pm 32.08$ & $638.00 \pm 72.38$ & $674.00 \pm 42.58$ & $681.67 \pm 25.66$ \\
\hline \multicolumn{5}{|l|}{ Females } \\
\hline $\mathrm{RBC}\left(\times 10^{6} / \mu \mathrm{L}\right)$ & $7.13 \pm 0.24$ & $6.96 \pm 0.39$ & $7.01 \pm 0.21$ & $7.08 \pm 0.17$ \\
\hline $\mathrm{WBC}\left(\times 10^{3} / \mu \mathrm{L}\right)$ & $8.17 \pm 0.87$ & $8.22 \pm 0.76$ & $8.17 \pm 0.12$ & $8.20 \pm 1.11$ \\
\hline Hemoglobin (g/dL) & $14.30 \pm 1.34$ & $14.27 \pm 1.72$ & $14.37 \pm 0.67$ & $13.07 \pm 2.21$ \\
\hline Hematocrit (\%) & $45.80 \pm 3.40$ & $45.57 \pm 3.67$ & $45.67 \pm 2.52$ & $40.80 \pm 5.66$ \\
\hline Neutrophils (\%) & $17.67 \pm 3.50$ & $16.67 \pm 2.08$ & $17.00 \pm 2.64$ & $18.33 \pm 4.72$ \\
\hline Eosinophils (\%) & $2.33 \pm 0.58$ & $2.00 \pm 1.00$ & $2.33 \pm 0.58$ & $2.67 \pm 1.15$ \\
\hline Basophils (\%) & $1.00 \pm 0.00$ & $0.67 \pm 0.58$ & $1.00 \pm 1.00$ & $1.00 \pm 0.00$ \\
\hline Monocytes (\%) & $2.67 \pm 1.15$ & $3.00 \pm 1.00$ & $2.67 \pm 0.58$ & $3.00 \pm 1.00$ \\
\hline Lymphocytes (\%) & $76.33 \pm 4.51$ & $77.67 \pm 2.52$ & $77.00 \pm 2.65$ & $75.00 \pm 4.36$ \\
\hline Platelets $\left(\times 10^{3} / \mu \mathrm{L}\right)$ & $689.33 \pm 25.48$ & $622.00 \pm 42.57$ & $654.33 \pm 33.32$ & $632.00 \pm 33.87$ \\
\hline
\end{tabular}

Values are expressed as Mean \pm SD in each sex group. Differences between the treated group and the control group were not significant. RBC, Red Blood Cell; WBC, White Blood Cell.

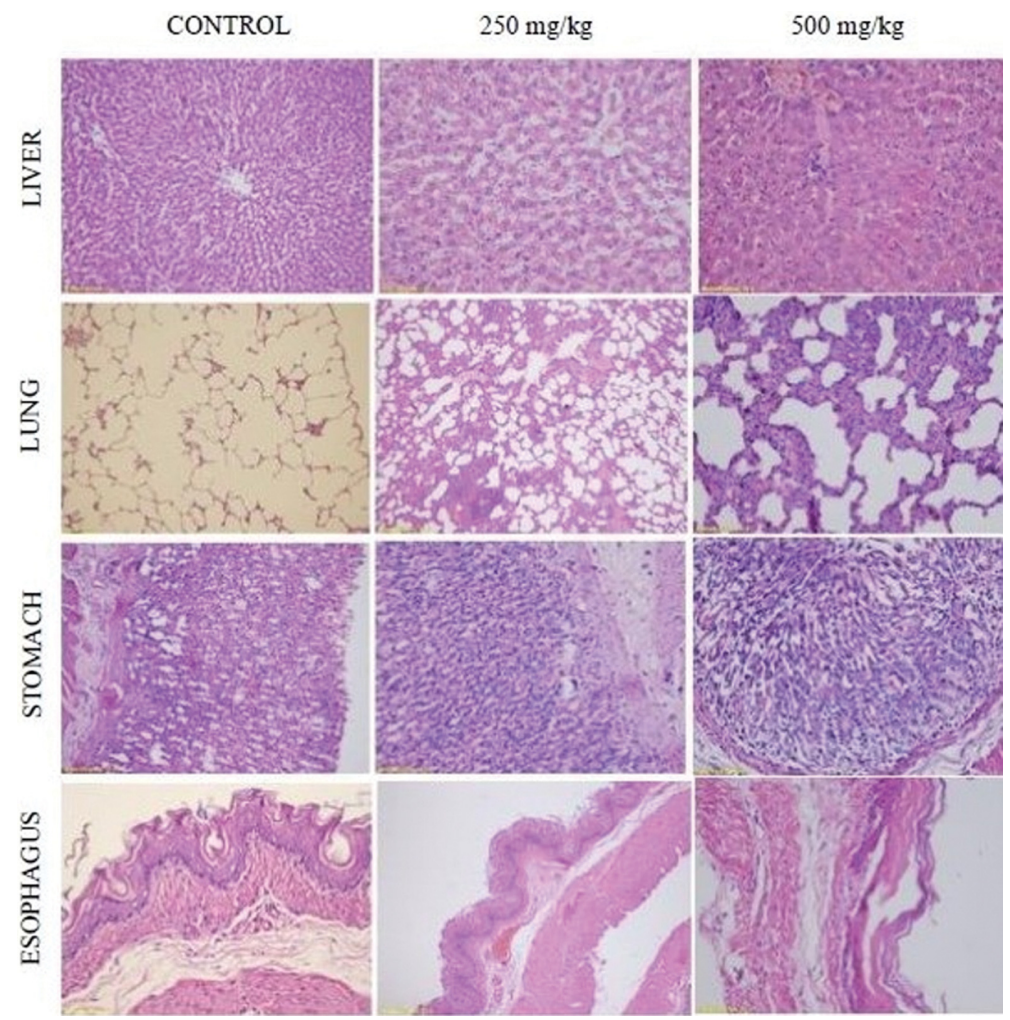

Fig. 2. Photomicrographs of the sections from liver, lung, stomach, and esophagus of rats treated with vehicle (control) and Thymus vulgaris essential oil over 28 days. H-E staining, $40 \times$. 
Histological findings. Microscopic examination of the organs from rats sacrificed after the 28-day treatment period showed no alteration in the kidney and spleen. However, a mild inflammatory infiltrate was observed in the liver in $70 \%$ of the cases for all three dose levels; 100 , 250 , and $500 \mathrm{mg} / \mathrm{kg}$ bw. Lungs of rats given doses of 100 and $250 \mathrm{mg} / \mathrm{kg}$ bw of essential oil showed a moderate inflammatory infiltrate in $65 \%$ of cases; whereas with a dose of $500 \mathrm{mg} / \mathrm{kg}$, the inflammatory infiltrate was severe, and in $45 \%$ of the cases hemorrhagic foci were also observed. The stomach showed a mild acute inflammatory infiltrate in one case $(10 \%)$ at a dose of $250 \mathrm{mg} / \mathrm{kg}$ bw, and in two cases (20\%) at $500 \mathrm{mg} / \mathrm{kg}$ bw (Fig. 2). In the esophagus, only one case $(10 \%)$ of moderate sub epithelial inflammatory infiltrate was observed at a dose of $500 \mathrm{mg} / \mathrm{kg}$ bw (Fig. 2).

\section{DISCUSSION}

The $2,000 \mathrm{mg} / \mathrm{kg}$ bw single oral dose caused the death of two rats (2/3) within $24 \mathrm{hr}$, preceded by the rapid onset of toxicity manifestations in the respiratory, central nervous, and autonomic systems. The intense burning of the nose observed in the animals could be due to the fact that the respiratory tract is innervated by primary sensory afferent nerves, which are activated by mechanical and chemical stimuli. The transient receptor potential cation channel, subfamily A, member 1 (TRPA1) channels are nonselective cation channels that are activated by a range of natural substances (23). When an odorous substance is sufficiently pungent, the trigeminal nerve, or vagal afferent $\mathrm{C}$ fibers, in the nose, mouth, and eyes are activated. This sensory system, called the common chemical sense (CCS), may have evolved as a warning system for potentially hazardous chemicals. It evokes sensations, such as irritation, tickling, burning, warming, cooling, and stinging in the nasal and oral cavities, and in the cornea, via pain receptors and the trigeminal nerve (24).

Histopathological alterations in the lungs of dead rats in the acute study are related to interstitial pneumonitis of chemical origin (consistent with capillaritis). This is probably due to the direct effect of the essential oil on the lung tissue, as it is a volatile compound. Essential oil is primarily eliminated via the airways, meaning that inflammatory infiltrates in the lung tissue are also related to TRPA1 activation, which is highly expressed in the sensory nerve cells that project vagal $\mathrm{C}$ fibers into the airways and lungs, where they play a role in the inflammatory response (23). In the 28-day toxicity study, concentration-dependent inflammatory infiltrates were also observed, being severe in the group with the highest dose $(500 \mathrm{mg} / \mathrm{kg} \mathrm{bw})$, where some cases with hemorrhagic foci were also observed (Fig. 3).

In a previous study we found that the main constituent of Thymus vulgaris essential oil is thymol, which represents $46.47 \%$ of the total constituents. Other constituents are $\gamma$-terpinene $(20.27 \%), p$-cymene $(15.80 \%), \alpha$-terpinene (2.84\%), $\beta$-myrcene (1.91\%); and in small amounts, $\alpha$ thujene, $\alpha$-pinene, camphene, $\alpha$-phellandrene, $d$-limonene, eucalyptol, caryophyllene, germacrene $\mathrm{D}, \gamma$-cadinene, and $\gamma$-muurolene (13).

It has been reported that thymol induces TRPA1 activation (25), so it is likely that the effects produced in the rats' respiratory system was, in part, due to the presence of this compound. It has also been reported that thymol presynaptically enhances spontaneous excitatory transmission (increases the release of L-glutamate) in lamina II (gelatinous substance) neurons by activating TRPA1 channels (26). This would explain, in part, the initial hyperactivity shown by the rats during the acute study. Likewise, it has been shown that both the essential oil of Thymus vulgaris and thymol inhibit the activity of acetyl cholinesterase (27), which may be related to the hyper-salivation that was observed after the administration of the $2,000 \mathrm{mg} /$ $\mathrm{kg}$ bw dose.

The manifestation of symptoms before death suggest that the toxic effect occurs mainly at the central nervous system (CNS) level, which leads to lethargy, coma, and death. The CNS is particularly vulnerable to toxic substances because it has very limited capacity to regenerate, and if the nerves are damaged they cannot be recovered. Behavioral changes may include deficits in cognitive function, effects on mood or sleep (CNS), and muscle conditions, such as weakness, numbness, and alterations in motor coordination (CNS and SNP) (28). Some of these manifestations were observed in this research after the administration of $2,000 \mathrm{mg} / \mathrm{kg}$ bw of essential oil. Since there were no alterations in the brain tissue of rats that received the lower dose $(300 \mathrm{mg} / \mathrm{kg} \mathrm{bw})$ of essential oil of Thymus vulgaris, it is possible that the neurotoxicity is related to an alteration of the neurotransmitters. Both CNS stimulation and CNS depression are manifestations of functional neurotoxicity, as they can alter the normal state of cognition, alertness, and coordination. The common effects of CNS depression include reduced respiratory and heart rate, blood pressure, temperature, and alertness, as well as partial loss of motor coordination. An overdose of depressant drugs can lead to loss of consciousness, coma, and death. Typical mechanisms of CNS depression include facilitation of $\mathrm{GABA}_{\mathrm{A}}$ and/or opioid activity, and inhibition of adrenergic activity and/or acetylcholine (28). With regard to this, it has been shown that thymol potentiates human $\mathrm{GABA}_{\mathrm{A}}$ receptors (29).

The histopathological alterations found in the kidneys during the acute oral toxicity study may be due to spontaneous lesions-the most common and important in rodents being chronic nephropathy. This lesion starts between three and six months of age and manifests through basophilic renal 
tubules, widening of the glomeruli membranes, interstitial fibrosis, cellular infiltrates foci, and glomerulosclerosis (30). In the 28-day toxicity study, histological changes were not observed, and serum urea and creatinine levels were also unaltered (Table 2).

The hepatic histopathological study, performed after the acute toxicity test, showed no alterations; whereas in the study with repeated doses over 28 days, only mild inflammatory infiltration was observed (Fig. 2). This is related to the results of the biochemical parameters, in which AST, ALT, alkaline phosphatase, total bilirubin, total protein, and albumin were within normal ranges (Table 2). However, the mild inflammatory infiltrate observed in the stomach (Fig. 2), and the moderate sub-epithelial inflammatory infiltrate in the esophagus (Fig. 2), in a minimum number of cases, could be related to the orogastric tube that was used for the administration of the Thymus vulgaris essential oil.

Body weight is an important indicator of toxicity. However, in the 28-day period of treatment with repeated doses of Thymus vulgaris, body weight was unaltered in female rats. Whereas in males there was a significant decrease in the last week of treatment, but only in the $500 \mathrm{mg} / \mathrm{kg}$ bw dose group (Fig. 1). Likewise, the relative weight of the organs was unaltered (Table 1). Therefore, the effect of treatment on weight is not relevant. On the other hand, the hematological parameters were not altered (Table 3), and the other biochemical parameters, such as total cholesterol, triglycerides, HDL, LDL, and glucose, remained unchanged (Table 2).

In other in vitro toxicity studies evaluating cell damage at the DNA level produced by thymol, the results were diverse. One study showed that this compound is not genotoxic in mammalian cells (31), but another study reported that thymol induced structural chromosomal aberrations and changes in frequency of micronuclei in human peripheral lymphocytes (32). Moreover, genotoxicity was dependent on the thymol concentration, so that in low concentrations did not cause DNA damage in human lymphocytes, but in higher concentrations produced a significant increase in damage (33). A similar result was observed in Chinese hamster lung fibroblast V79 cells, indicating a lack of thymol clastogenic activity in biologically relevant concentrations (34). In addition, thymol did not show any mutagenic activity in Salmonella with the Ames test, nor did it exhibit a genotoxic effect in the Caco-2 cell line of human colon carcinoma (35). The essential oil of Thymus vulgaris did not induce significant DNA damage in vitro in the human embryonic lung cells HEL 12469 (7).

There are no previous reports of acute oral toxicity from repeated doses of Thymus vulgaris essential oil, and an average oral rat $\mathrm{LD}_{50}=1,220 \mathrm{mg} / \mathrm{kg}$ bw dose was reported only for thymol (18). According to the results obtained from the oral acute toxicity test, and in accordance with the Globally Harmonized Classification System (GHS), established by the OECD (21), the essential oil of Thymus vulgaris falls into category $4(>300-2,000 \mathrm{mg} / \mathrm{kg} \mathrm{bw})$, with an $\mathrm{LD}_{50}$ cut-off $=1,000 \mathrm{mg} / \mathrm{kg}$ bw. This result, according to Tisserand and Boyd (18), is classified as moderately toxic.

Our studies reveal that the essential oil of Thymus vulgaris has moderate oral toxicity according to the results of the acute test. Whereas the results of the 28-day oral toxicity test suggest that the no-observed-adverse effect level (NOAEL) is greater than $250 \mathrm{mg} / \mathrm{kg} /$ day. These results could be of interest in promoting the research of other in vitro and in vivo toxicity tests to establish the safety of thyme oil. It is advisable not to use high doses to avoid possible harmful effects to health.

\section{ACKNOWLEDGMENTS}

The authors would like to thank the vice-director of the National University of San Marcos, Peru for the financial support that has made this research possible.

\section{CONFLICT OF INTEREST}

The authors declare that there are no conflicts of interest.

Received June 28, 2018; Revised December 22, 2018; Accepted January 16, 2019

\section{REFERENCES}

1. Brack, A. (1999) Encyclopedic Dictionary of Useful Plants of Peru, Center for Andean Regional Studies "Bartolomé de las Casas"/United Nations program for development, Cuzco, p. 500 .

2. Al-Bayati, F.A. (2008) Synergistic antibacterial activity between Thymus vulgaris and Pimpinellaanisum essential oils and methanol extracts. J. Ethnopharmacol., 116, 403406.

3. Mohsenzadeh, M. (2007) Evaluation of antibacterial activity of selected Iranian essential oils against Staphylococcus aureus and Escherichia coli in nutrient broth medium. Pak. J. Biol. Sci., 10, 3693-3697.

4. Zu, Y., Yu, H., Liang, L., Fu, Y., Efferth, T., Liu, X. and Wu, N. (2010) Activities of ten essential oils towards Propionibacterium acnes and PC-3, A-549 and MCF-7 cancer cells. Molecules, 15, 3200-3210.

5. Rojas, J., Ruiz, J., Almonacid, R., Ortiz, J., Palomino, M., Huaroto, L., Collahua, E., Chavez, R. and Anampa, A. (2016) Antibacterial activities of essential oils from three medicinal plants in combination with EDTA against methicillin-resistant Staphylococcus aureus. Br. Microbiol. Res. J., 17, 1-10.

6. Radaelli, M., Parraga da Silva, D., Weidlich, L., Hoehne, L., Flach, A. and Alves da Costa, L.A. (2016) Antimicrobial activities of six essential oils commonly used as condiments 
in Brazil against Clostridium perfringens. Braz. J. Microbiol., 47, 424-430.

7. Puškárová, A., Bučková, M., Kraková, L., Pangallo, D. and Kozics, K. (2017) The antibacterial and antifungal activity of six essential oils and their cyto/genotoxicity to human HEL 12469 cells. Nature, 7, 1-11.

8. Soković, M., Glamoclija, J., Cirić, A., Kataranovski, D., Marin, P.D., Vukojević, J. and Brkić, D. (2008) Antifungal activity of the essential oil of Thymus vulgaris L. and thymol on experimentally induced dermatomycoses. Drug Dev. Ind. Pharm., 34, 1388-1393.

9. Rojas, J., Ortiz, J., Jauregui, J., Ruiz, J. and Almonacid, R. (2015) Essential oil of Thymus vulgaris L. (thyme), its combination with EDTA against Candida albicans and formulation of a cream. An. Fac. Med., 76, 235-240.

10. Flores, F.C., Beck, R.C. and Da Silva, C. (2016) Essential oils for treatment for onychomycosis: a mini review. Mycopathologia, 181, 9-15.

11. Al-Shahrani, M.H., Mahfoud, M., Anvarbatcha, R., Athar, T. and Al Asmari, A. (2017) Evaluation of antifungal activity and cytotoxicity of Thymus vulgaris essential oil. Pharmacogn. Commn., 7, 34-40.

12. Pensel, P.E., Maggiore, M.A., Gende, L.B., Eguaras, M.J., Denegri, M.G. and Elissondo, M.C. (2014) Efficacy of essential oils of Thymus vulgaris and Origanum vulgare on Echinococcus granulosus. Interdisc. Persp. Infect. Dis., 2014, 693289.

13. Rojas, J., Palacios, O. and Palomino, M. (2015) Chemical composition and anti-Trypanosoma cruzi effect of Thymus vulgaris L. (Thyme) essential oil and its main component, thymol, in mice. Am. J. Pharm.Pharmacol., 2, 21-27.

14. Grespan, R., Aguiar, R.P., Giubilei, F.N., Fuso, R.R., Damião, M.J., Silva, E.L., Mikcha, J.G., Hernandes, L., Bersani Amado, C. and Cuman, R.K. (2014) Hepatoprotective effect of pretreatment with Thymus vulgaris essential oil in experimental model of acetaminophen-induced injury. Evid. Based Complement. Alternat. Med., 2014, 954136.

15. Sammi, S.R., Trivedi, S., Rath, S.K., Nagar, A., Tandon, S., Kalra, A. and Pandey, R. (2017) 1-Methyl-4-propan-2-ylbenzene from Thymus vulgaris attenuates cholinergic dysfunction. Mol. Neurobiol., 54, 5468-5481.

16. Kim, M.J., Lee, M.J., Lee, Y.-H., Park, S.H., Kim, D., Park, C.B., Kang, J.S. and Kang, J.-K. (2017) Subchronic oral toxicity study of Acanthopanax divaricatus var. albeofructus in rats. Toxicol. Res., 33, 15-23.

17. Park, S.-J., Lim, K.-H., Noh, J.-H., Jeong, E.J., Kim, Y.-S., Han, B.-C., Lee, S.-H. and Moon, K.-S. (2013) Subacute oral toxicity study of Korean red ginseng extract in spraguedawley rats. Toxicol. Res., 29, 285-292.

18. Tisserand, R. and Young, R. (2013) Toxicity in Essential Oil Safety (2nd edition), Churchill Livingstone, Elsevier, New York, pp. 23-38.

19. Lahlou, M. (2004) Methods to study the phytochemistry and bioactivity of essential oils. J. Phytother. Res., 18, 435-448.

20. National Research Council (2011) Guide for the Care and Use of Laboratory Animals (8th edition), The National Academies Press, Washington.

21. Organisation for Economic Cooperation and Development (2001) Acute Oral Toxicity-Acute Toxic Class Method.
Guideline 423.

22. Organisation for Economic Cooperation and Development (2008) Repeated Dose 28-Day Oral Toxicity Study in Rodents, Guideline for the Testing of Chemicals, Test Guideline 407.

23. Belvisi, M.G., Dubuis, E. and Birrell, M.A. (2011) Transient receptor potential A1 channels: insights into cough and airway inflammatory disease. Chest, 140, 1040-1047.

24. Tisserand, R. and Young, R. (2013) Essential oil safety in The Respiratory System (2nd edition). Churchill Livingstone, Elsevier, New York, pp. 99-110.

25. Lee, S.P., Buber, M.T., Yang, Q., Cerne, R., Cortés, R.Y. and Sprous, D.G. (2008) Thymol and related alkyl phenols activate the hTRPA1 channel. Br. J. Pharmacol., 153, 17391749.

26. Xu, Z.H., Wang, C., Fujita, T., Jiang, C.Y. and Kumamoto, E. (2015) Action of thymol on spontaneous excitatory transmission in adult rat spinal substantia gelatinosa neurons. Neurosci. Lett., 606, 94-99.

27. Jukic, M., Politeo, O., Maksimovic, M., Milos, M. and Milos, M.L. (2007) In vitro acetylcholinesterase inhibitory properties of thymol, carvacrol and their derivatives thymoquinone and thymohydroquinone. Phytother. Res., 21, 259261.

28. Tisserand, R. and Young, R. (2013) Essential oil safety in The Nervous System (2nd edition). Churchill Livingstone, Elsevier, New York, pp. 131-146.

29. Priestley, C.M., Williamson, E.M., Wafford, K.A. and Sattelle, D.B. (2003) Thymol, a constituent of thyme essential oil, is a positive allosteric modulator of human $\mathrm{GABA}_{\mathrm{A}}$ receptors and a homo-oligomeric $\mathrm{GAB}_{\mathrm{A}}$ receptor from Drosophila melanogaster. Br. J. Pharmacol., 140, 1363-1372.

30. Lagarto, A., Tillán, J., Bueno, V., Chávez, I., Guerra, I. and Vega, Y. (2005) Acute oral and subchronic toxicity in rats of a lyophilized aqueous extract of Ocimumtenuiflorum L. Rev. Toxicol., 22, 175-179.

31. Maisanaba, S., Prieto, A., Puerto, M., Gutiérrez-Praena, D., Demir, E. and Marcos, R. (2015) In vitro genotoxicity testing of carvacrol and thymol using the micronucleus and mouse lymphoma assays. Mutat. Res., 784, 37-44.

32. Buyukleyla, M. and Rencuzogullari, E. (2009) The effects of thymol on sister chromatid exchange, chromosome aberration and micronucleus in human lymphocytes. Ecotoxicol. Environ. Saf., 72, 943-947.

33. Aydın, S., Başaran, A. and Başaran, N. (2005) The effects of thyme volatiles on the induction of DNA damage by the heterocyclic amine IQ and mitomycin C. Mutat. Res., 581, 4353.

34. Ündeğer, Ü., Başaran, A., Degen, G.H. and Başaran, N. (2009) Antioxidant activities of major thyme ingredients and lack of (oxidative) DNA damage in V79 Chinese hamster lung fibroblast cells at low levels of carvacrol and thymol. Food Chem. Toxicol., 47, 2037-2043.

35. LLana-Ruiz-Cabello, M., Maisanaba, S., Puerto, M., Prieto, A.I., Pichardo, S., Jos, A. and Camean A.M. (2014) Evaluation of the mutagenicity and genotoxic potential of carvacrol and thymol using the Ames Salmonella test and alkaline, Endo IIIand FPG-modified comet assays with the human cell line Caco-2. Food Chem. Toxicol., 72, 122-128. 